Dermatology 2010;220:54

DOI: $10.1159 / 000242379$

\section{Clinical and Dermoscopic Features of Nevi in Children}

Paula Aguilera, Susana Puig

Melanoma Unit, Dermatology Department, Hospital Clínic de Barcelona, Barcelona, Spain

Key Words

Nevi, dermoscopy $\cdot$ Nevi, children

Thank you very much for your kind attention to our paper. My co-authors and I would like to thank Dr. Alaibac and his group [1] for reporting the clinical and dermoscopic characteristics of nevi in children from a population different from ours in Barcelona. We think it is very important that studies from different countries and populations are reported and also that the age group and the subset of patients are specified so that different studies can be compared. Dermoscopic characteristics have been reported in the last few years, but we think there is still a lack of reports, and only few papers referring to dermoscopic patterns in children have been published. That is why we would like to thank the group from Padova for their effort, in this way contributing to enlarge the data about dermoscopic patterns in children.

One of the main differences we found in both studies is the mean number of nevi, which was 1.5 in the children from Padova, whereas ours was 17.5. Both studies included nevi less than $2 \mathrm{~mm}$ in diameter, so this is not a source of this difference. Probably, it is the age of the patients. In our study we included a cohort of 180 children aged 1-15 years, whereas Alaibac and co-workers included 81 preschool children aged only $2-6$ years. Taking into account that the number of nevi clearly increases with age $[2,3]$, the difference in age of the populations is probably the explanation because the mean number of nevi increases as age does (e.g. from 1.50 nevi in the 1-year-old group to 30.58 nevi in the group aged 15 years).

Another difference we can observe between the two populations is the predominant skin type. Clearly our population has a darker skin type, as the population of Padova could be more like individuals from central-northern Europe than ours from Barcelona.
Finally and interestingly, one of the other differences found is the predominant dermoscopic pattern. We found percentages of pattern predominance similar to those of the group of Padova, except for the reticular pattern, which the authors found in $37 \%$ of cases; in our population, this pattern was found in $15.6 \%$ of cases. Taking into account that in our results we found age to be an independent risk factor for the dominant reticular pattern, one could expect that in our population aged 1-15 years a higher percentage of the dominant reticular pattern was found than in the population from Padova. We hypothesize that this incongruence could be due to a different selection of patients. Whereas in our study $75 \%$ of patients consulted for other dermatologic complaints besides pigmented lesions, all patients included by Alaibac and co-workers were examined at the pigmented lesion clinic. This subset of patients consulting for melanocytic lesions may be those children destined to develop dysplastic nevi. Patients with a tendency to develop atypical moles may have a higher proportion of reticulated nevi than the general population of the same age. The presence of a multicomponent pattern in some of these patients can be a marker of this. There may be a case selection, as we reported on a population of mostly healthy children whereas the other study included mostly patients visiting a pigmented lesion clinic.

Further studies with similarly aged patients are needed to understand the behavior of nevi and to define dermoscopic characteristics among populations.

\section{References}

1 Belloni Fortina A, Zattra E, Romano I, Bernardini B, Alaibac M: Clinical and dermoscopic features of nevi in preschool children in Padua. Dermatology DOI: 10.1159/000240017.

2 Aguilera P, Puig S, Guilabert A, Julià M, Romero D, Vicente A, González-Enseñat MA, Malvehy J: Prevalence study of nevi in children from Barcelona. Dermatology 2009;218:203-214.

3 Oliveira SA, Geller AC, Dusza SW, Marghoob AA, Sachs D, Weinstock MA, et al: The Framingham school naevus study. Arch Dermatol 2004; 140:545-551.

Paula Aguilera

Melanoma Unit, Dermatology Department

Hospital Clínic de Barcelona, Villarroel 170

ES-08036 Barcelona (Spain)

E-Mail aguilisha@hotmail.com
KARGER

(c) 2009 S. Karger AG, Basel

Fax +4161306 1234

E-Mail karger@karger.ch

www.karger.com
Accessible online at: www.karger.com/drm 